\section{WHAT IS HEPATITIS B?}

Hepatitis B is an infection of the liver caused by a virus called hepatitis $B$. 'Hepatitis' means 'inflammation or swelling of the liver'.

\section{WHAT ARETHE SYMPTOMS OF INFECTION?}

Many people will have no symptoms when they are newly infected. When symptoms are present they usually include jaundice (yellowing of the skin and eyes), dark urine, fatigue, abdominal pain, loss of appetite, nausea, vomiting, and joint pain.

\section{HOW DOES HEPATITIS B INFECTION AFFECT PEOPLE INTHE LONG TERM?}

Once infected, people will either:

- clear the infection and have no further problems;

- not clear the infection and become chronically infected. People with chronic infection are sometimes known as 'carriers'.

\section{CHRONIC INFECTION}

Some carriers of hepatitis B can have health problems related to the infection, while others will not. Whether a person clears the infection or becomes chronically infected depends mainly on their age: 90 per cent of babies, 2050 per cent of children aged 1-5 years, 1-10 per cent of older children and adults, become chronically infected. People with chronic infection are usually infectious for life, and may develop ongoing hepatitis. After many years this can result in complications such as cirrhosis or liver cancer.

\section{HOW DO YOU CATCH HEPATITIS B ?}

Hepatitis B is passed on to others when blood or body fluids (for example, saliva, semen, and vaginal secretions) that contain the hepatitis $B$ virus enters a person's body through:

- broken skin,

- mucous membranes,

- the bloodstream by:

- sharing contaminated injecting equipment, or using needles after an infected person, or a needlestick injury;

- having sex with an infected person without using a condom.

Hepatitis B can also be passed on to a baby at birth from an infected mother.

People at risk of infection include:
- injecting drug users;

- babies born to infected women;

- people with multiple sexual partners;

- sexual contact with carriers;

- men who have sex with men;

- haemodialysis patients;

- health care workers;

- children of people born in countries with high rates of hepatitis B infection;

- household contact with people infected with hepatitis B.

\section{IS THERE A TEST FOR HEPATITIS B?}

A blood test can show if a person has been infected with hepatitis B in the past, and whether a person is chronically infected. Other tests, such as a liver function test, can show if any damage has been done to the liver.

\section{IS THERE ANY TREATMENT FOR HEPATITIS B ?}

Viral infections such as hepatitis B can be very difficult to treat. Some people may benefit from treatment. Talk to your doctor about possible treatments. People with chronic infections should take care of their livers. Drinking alcohol can make your liver disease worse.

\section{PREVENTION}

\section{Immunisation}

Hepatitis B vaccine is very effective in preventing infection:

- all children should be vaccinated at birth, and aged two, four, and six months of age. These vaccines are given by your doctor or clinic as part of the routine childhood vaccinations;

- all 10 year old children who were not immunised as babies should receive three doses of vaccine from their general practitoner;

- these vaccines are free.

Others who should be vaccinated are:

- those who have household or sexual contact with carriers;

- men who have sex with men;

— people with sexually transmissible infections;

— injecting drug users;

— haemodialysis patients;

- people who receive blood products for clotting disorders;

- people with chronic liver disease or hepatitis $\mathrm{C}$ infection; 
- residents and staff of facilities for persons with intellectual disabilities;

— inmates and staff of correctional facilities;

- health care workers;

- embalmers;

— staff of emergency departments and services.

\section{PREVENTING SPREAD}

To prevent the spread of hepatitis B infection:

- use condoms if you are having sex with new sexual partners or with partners infected with hepatitis B;

- if you are pregnant, you should have a blood test for hepatitis B; infants born to hepatitis B infected mothers should be given hepatitis B immunoglobulin and vaccine within 12 hours after birth;

- do not share injecting equipment;

- do not share personal items that may have blood on them, (for example, razors or toothbrushes);
- if having a tattoo or your body pierced, make sure that the practitioner uses disposable and sterile equipment.

If you are infected:

- do not donate blood, organs or tissue if you have hepatitis $\mathrm{B}$;

- advise your doctor and dentist that you are infected;

- be very careful to make sure that other people are not exposed to your blood or body fluids. Clean up any spills with a paper towel and clean thoroughly with detergent and water until no obvious stains are left. If a large blood spill occurs on carpet, it may need to be shampooed or steam cleaned;

- cover your wounds with a waterproof bandage;

- use condoms with new sexual partners.

For further information please contact your local Public Health Unit, Community Health Centre, or doctor.

September 2001.

\section{COMMUNICABLE DISEASES, NSW: SEPTEMBER 2001}

\section{TRENDS}

Reports of influenza began to increase in late June. The majority of cases of influenza diagnosed by major laboratories in NSW have been influenza A, while a small proportion have been influenza $B$.

Following a promising decline in notifications earlier in the year, pertussis has re-emerged (Figure 1). Almost 2,000 cases have been reported this year across the state through to July 2001. The highest rates of infection remain in children of school age. This increase is particularly concerning because, historically, cases rise in spring, which begins this month.
Six cases of Legionnaires disease were reported in July. Three were due to Legionella longbeachae, thought to be transmitted largely by breathing in dust from soil or potting mix. Three were due to Legionella pneumophila, thought to be transmitted largely by breathing in aerosols of contaminated water. These cases were unrelated.

Twenty-four cases of meningococcal disease were notified across the state in July (Table 1), which is in line with seasonal expectations. Hepatitis A notifications increased slightly in July with 21 cases notified. 